Article

\title{
Characterizing Spatial Variability in Soil Water Content for Precision Irrigation Management
}

\author{
Alfonso de Lara ${ }^{1}$, Raj Khosla ${ }^{1, *}$ and Louis Longchamps ${ }^{2}$ \\ 1 Department of Soil and Crop Sciences, Colorado State University, Fort Collins, CO 80523-1170, USA; \\ adelara@rams.colostate.edu \\ 2 Agriculture and Agri-Food Canada, St-Jean-sur-Richelieu, QC, Canada; louis.longchamps@canada.ca \\ * Correspondence: raj.khosla@colostate.edu; Tel.: +1-970-491-1920
}

Received: 15 March 2018; Accepted: 18 April 2018; Published: 24 April 2018

\begin{abstract}
Among one of the many challenges in implementing precision irrigation is to obtain an accurate characterization of the soil water content (SWC) across spatially variable fields along the crop growing season. The accuracy of characterizing SWC has been tested primarily on a small-scale and has received little attention from the scientific community at the field scale. Hence, the objective of this study was to assess the characterization of the spatial distribution of soil water content at the field scale by the apparent electrical conductivity (ECa). In evaluating the current aim, ECa survey was compared against repeated measurements of SWC at five depths using neutron probe. Results showed that mean SWC was different across ECa derived management zones, which indicates that on a macro-scale, soil ECa could effectively characterize the mean differences in SWC across management zones. Results also showed that deep ECa $(0-150 \mathrm{~cm})$ survey outperformed shallow survey $(0-75 \mathrm{~cm})$. Considering other soil properties, such as organic matter content and salt content, further improved the relationship between SWC and ECa.
\end{abstract}

Keywords: prescription map; small-scale; field scale; spatial distribution; management zones

\section{Introduction}

Fields exhibit spatial heterogeneity for several soil characteristics that influence soil water content (SWC), such as soil type and topography [1]. Common agricultural practice is to adjust the irrigation rate for the driest regions of the field, to ensure that no part of the field is under-irrigated [2]. This practice results in the suboptimal utilization of water in many other parts of the field. Available water-holding capacity (AWC) of soil is the maximum amount of water accessible to crops in the root zone [3]. Hence, a precise delineation of sub-field areas possessing similar characteristics, such as delineating site-specific management zones (SSMZ) [4,5], is key to precise irrigation management [6]. For precision irrigation, delineating SSMZ relies on soil hydraulic properties, which define the optimal soil water parameters for each zone [7]. Variable Rate Irrigation (VRI) systems have made it technologically feasible to vary the amount of water applied across a field [1]. Thereby, VRI systems present an opportunity to improve water use efficiency by targeting optimal water rates needed within each zone.

Currently, variable rate irrigation strategies are extensively based on measuring apparent soil electrical conductivity apparent electrical conductivity (ECa) [7-9]. However, the soil properties that most influence ECa vary depending on the particular field being studied [10]. Furthermore, research has shown that a single study area can include different soil ECa controlling factors [11]. To characterize SWC, commercial agricultural retailers in the USA are measuring soil ECa as a major parameter without accounting for possible influence of other soil properties. An accurate characterization of 
spatial variability in SWC is pivotal for management of water using precision irrigation systems. In addition, potential interactions with other variables should not be ignored.

Previous studies showed a significant correlation between SWC and soil ECa and the estimation of AWC using regression models [7,12]. Likewise, Sheets and Hendrickx [13] demonstrated the feasibility of the soil ECa using simple linear models in assessing SWC over time. Review of the current literature indicates that no studies to date have explored this relationship at field scale. The objectives of this study were (1) to assess how consistently soil ECa derived management zones characterize SWC at the field scale and (2) to determine whether apparent soil electrical conductivity coupled with additional soil properties could further improve the characterization of SWC.

\section{Materials and Methods}

\subsection{Study Sites}

This study was conducted during 2012 on a 4.8 ha field located at the Agricultural Research Development \& Education Center (ARDEC), Fort Collins, CO, USA ( $40^{\circ} 39^{\prime} 57.4^{\prime \prime}$ N, $104^{\circ} 59^{\prime} 53.1^{\prime \prime}$ W). This site corresponds to the south portion of a field under a pivot irrigation system. The soil type is a Kim loam, classified as fine-loamy, mixed, active, mesic Ustic-Torriorthents (Soil Survey Staff, 2000). Based on corresponding soil samples, the texture was classified as sandy clay loam. The slope of the field is $0.9 \%$ in a single plane gradient. The field has been under conventional tillage continuous maize (Zea mays L.) cropping system for the past 10 years.

\subsection{Soil Water Content Data Collection}

Soil water content data were collected utilizing a neutron probe (Model 503 DR Hydroprobe, CPN International, Martinez, CA, USA). A total of 41 neutron probe (NP) access tubes were installed. Every access tube was geo-located using a differentially-corrected Trimble ${ }^{\mathrm{TM}}$ (Sunnyvale, CA, USA) Ag 114 global positioning system unit (DGPS). Soil water data were collected at five soil depths $(15,45$, 75,105 and $135 \mathrm{~cm}$ ). Data were acquired 13 times during the growing season, on a weekly basis, from 1 June to 24 September 2012. Figure 1 depicts the distribution of the neutron probes in the field.

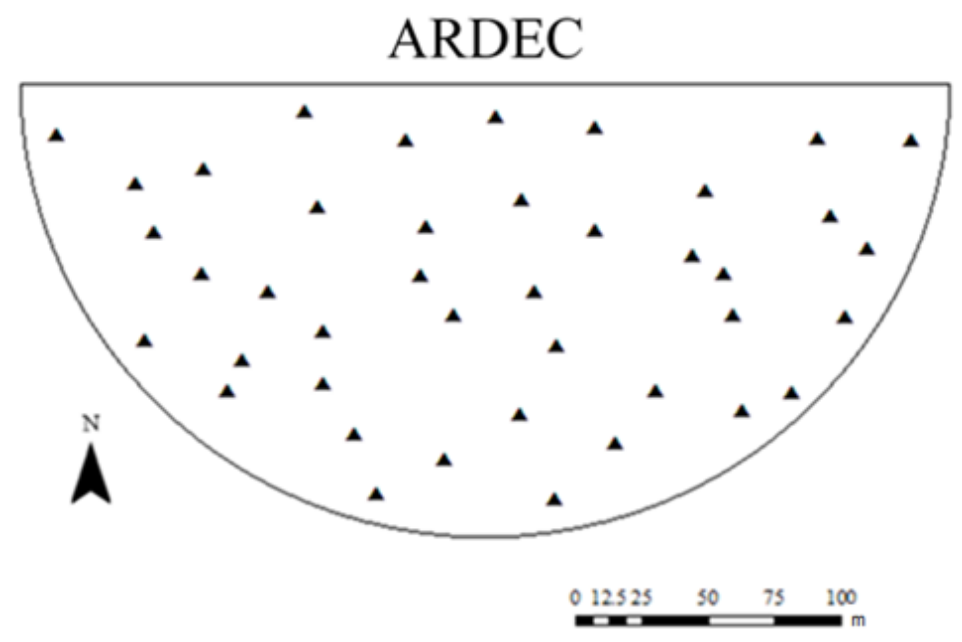

Figure 1. Map of the study field at Agricultural Research, Development and Education Center showing the location of neutron probe access tubes.

\subsection{Soil Sampling and Analysis}

Soil samples were taken to a depth of $60 \mathrm{~cm}$ and collected at 84 locations (not co-located with NP access tubes) on 8 April 2012. Agvise laboratories (Benson, NE, USA) performed routine soil tests and texture (clay, silt and sand) analysis. Soil tests included organic matter (\%), soluble salts ( $\mathrm{dS} \mathrm{m}^{-1}$ ) 
and CEC (meq $100 \mathrm{~g}^{-1}$ ). Minimum, mean and maximum values of chemical and physical properties analyzed are shown in Table 1.

Table 1. Soil samples collected at $0-60 \mathrm{~cm}$ soil depth with the minimum, mean and maximum values for sand, silt, clay, $\mathrm{pH}$, organic matter, soluble salts, and cation exchange capacity.

\begin{tabular}{cccccccc}
\hline Depth & Descriptive & Sand & Silt & Clay & OM & Salts & CEC \\
\hline $\mathbf{c m}$ & Statistics & & $\%$ & & $\%$ & dS $^{-\mathbf{1}}$ & \\
\hline \multirow{3}{*}{$0-60$} & min. & 45.4 & 13.07 & 31.35 & 1.26 & 0.53 & 29.83 \\
& mean & 48.35 & 16.95 & 34.62 & 1.61 & 0.59 & 31.65 \\
& max. & 56.63 & 19.33 & 35.62 & 1.87 & 0.69 & 32.2 \\
\hline
\end{tabular}

\subsection{Soil Apparent Electrical Conductivity Data Collection}

Sensor EM38MK2 (Geonics Limited, Mississauga, ON, Canada) was combined with a DGPS and data loggers mounted on an all-terrain vehicle were used to acquire high-resolution soil ECa readings when the soil was at field capacity. For maneuverability, the vehicle traveled in the direction of crop rows in a series of parallel transects spaced at 8 to $12 \mathrm{~m}$ intervals. The total number of observations was slightly below 2900, approximately one observation at every two meters. The EM38 was in vertical mode and collected datasets at two depths. The depths corresponded to a "deep" reading (i.e., $0-150 \mathrm{~cm}$ ), and a "shallow" reading (i.e., $0-75 \mathrm{~cm}$ ).

\subsection{Statistical ANALYSIS (ECa Classification)}

Management Zone Analyst (MZA) software (University of Missouri-Columbia) was used to determine the optimum number of zones [14]. In addition to the suggested optimal number of zones, as per MZA software results, three zone maps were calculated for every soil ECa reading for comparison with the approach similar to that practiced by the commercial agricultural retailers.

\subsection{ECa to Assess SWC}

The soil ECa zones derived from the deep ECa reading $(0-1.5 \mathrm{~m})$ were evaluated with the average SWC for the soil depth down to $1.35 \mathrm{~m}$, and the ECa zones derived from the shallow ECa reading $(0-0.75 \mathrm{~m})$ were evaluated with the average SWC for the soil depth down to $0.75 \mathrm{~m}$. Linear mixed models (LMM) were used to explain the relationship between SWC values and ECa derived management zones. The temporal SWC variations throughout the season were considered in the LMM as "random effects", that is to say, different model intercepts between each NP and SWC. The function "Imer" from the "Ime4" package [15] of the R statistical software [16] was used to create the LMM. Separation of the mean SWC among the ECa zones was performed using least squares means with the function "lsmeans" from the "lsmeans" package [17]. To detect statistical differences in SWC and ECa derived zones, least-squares means of SWC across each ECa management zones maps were calculated ( $p$-value $<0.05)$.

\subsection{Soil ECa Coupled with Soil Properties}

To evaluate any increase in the SWC estimation accuracy, interpolated (ordinary kriging) ECa values (before classification) were combined with organic matter, soluble salts, cation exchange capacity and clay content as SWC predictors. The analysis included only the ECa values from the derived ECa zones depths that significantly explained SWC in the previous analysis. The "dredge" function, from the "MuMIn" package for R statistical software [18], was used to test the addition of soil properties as explanatory variables to the interpolated ECa values. The ratio of the sample size to the number of predictors was less than 40 . Hence, the corrected version of the Akaike Information Criteria (AICc) guided the automatic ranking of the models by the SWC explanatory power [19]. ANOVA was used to 
determine significant differences between the first and second model with the function "anova" from the package "stats" [20].

\section{Results and Discussion}

\subsection{ECa Derived Management Zone Maps}

At the neutron probe access tube locations across the field, the mean value of deep ECa was $71 \mathrm{mS} \mathrm{m}^{-1}$, and it ranged from 64 to $81 \mathrm{mS} \mathrm{m}^{-1}$. The mean value of shallow ECa was $20.49 \mathrm{mS}$ $\mathrm{m}^{-1}$, and it ranged from 16 to $30 \mathrm{mS} \mathrm{m}^{-1}$. According to the MZA software, the optimal number of zones were two and four at ECa measurement depths of $1.5 \mathrm{~m}$ and $0.75 \mathrm{~m}$, respectively. As previously mentioned, to compare with the approach similar to that practiced by commercial retailers, three zones were also calculated for each soil ECa depth.

\subsection{ECa Derived Management Zones to Assess SWC}

Across all dates and depths of soil moisture measurements, the volumetric SWC ranged from 0.09 to $0.45 \mathrm{~m}^{3} \mathrm{~m}^{-3}$. Only the deep ECa-zones demonstrated differences in SWC ( $p$-value $\left.<0.05\right)$, and the two-zone map performed better than the three-zone map, as recommended by MZA (Figure 2).
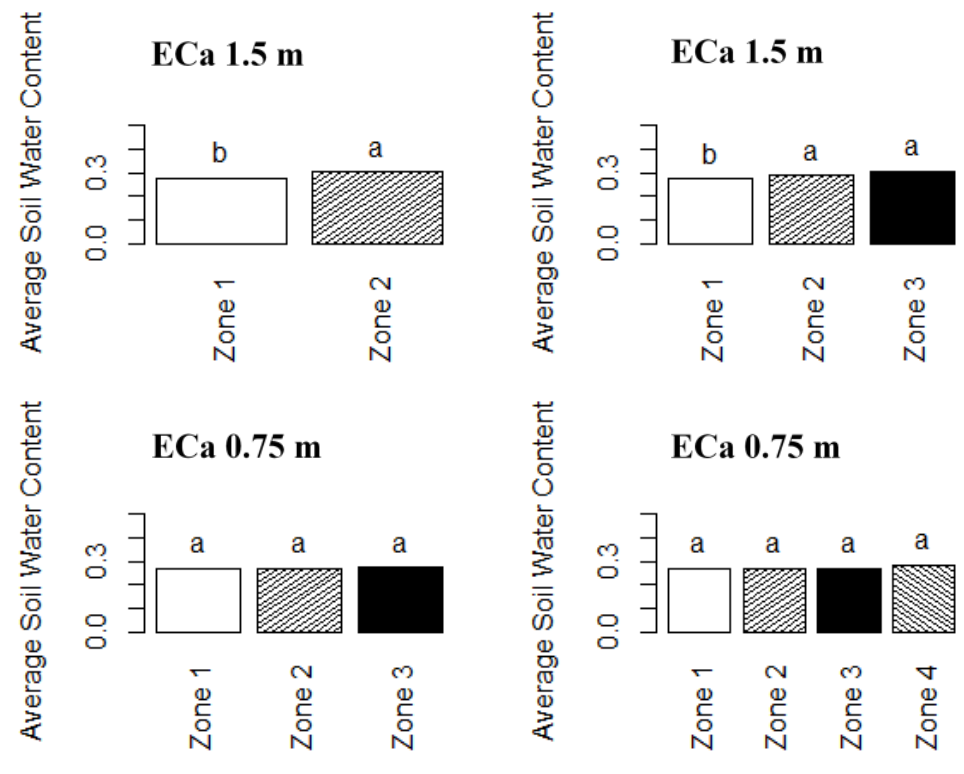

Figure 2. Mean soil water content across apparent electrical conductivity derive management zones for ARDEC. Different letters are significantly different ( $p$-value $<0.05)$.

The results of this study showed that with an inappropriate number of zones, there could be a confounded characterization of the spatial variability of SWC. This may be due to the creation of an unneeded management zone, or the lack of creation of a needed zone. Forcing the classification from two to three zones seemed to create a transitional zone that overlapped values from other zones, thus not representing a logical soil water management zone. This means that values of the neutron probes within the transitional zone were similar to another zone, and equivalent water management for both would be more logical. MZA software appears to be a useful tool to determine the number of zones to be delineated for precision irrigation purposes. Likewise, Hezarjaribi and Sourell [12] used similar software to successfully determine the accurate number of ECa zones to characterize SWC.

The lowest quantity of zones from the shallow ECa readings showed higher fuzziness index values. This finding suggests that the shallow sensing seemed to have a higher noise (i.e., soil properties affecting ECa other than SWC) to signal ratio compared to the deeper configuration. Despite Hezarjaribi and Sourell [12] also reporting a higher sensitivity of the shallow ECa measurements to the near-surface 
material, the depth that best fitted their field was also the shallow ECa reading. In sum, results from this study suggest that the ECa relationship with SWC not only depends on the horizontal nature of the field characteristics but also on its variability in soil depth, suggesting that zones should reflect the depths where the bulk of the roots are located. Hence, water management zones may change along the season as suggested by Longchamps et al., [21].

Results from this study also suggest that the soil ECa measurements could potentially provide useful information in characterizing in-field SWC variability, consistently throughout the season. However, it is logistically infeasible to acquire soil ECa measurements multiple times during the growing season for a field with a standing crop. Nonetheless, management zone delineation should be supervised when using soil ECa, i.e., one zone delineation procedure may not be suitable for all fields.

\subsection{ECa Coupled with Other Soil Properties to Enhance the Delineation of SWC Management Zones}

The deep soil ECa map of two zones was the best to explain the differences in SWC across NP locations. Therefore, the "full model" consisted of the interpolated soil ECa values of $1.5 \mathrm{~m}$ depth combined with the soil properties as predictors in the automated model selection. Results of the automated model selection are shown in Table 2. By combining soil properties with the base model, SWC assessment was improved (ANOVA test, $p$-value $<0.05$ ). The best model (lowest AICc value), included organic matter and salt content. The second best was the simplest model (base model), which utilized only the interpolated soil ECa values of $1.5 \mathrm{~m}$ depth as the predictor of the SWC. Management zone boundaries using only ECa or using ECa plus organic matter and salinity are juxtaposed in Figure 3.

Table 2. Automated model selection output for the first five models by rank. Full model consisted in the kriged apparent electrical conductivity (values of $1.5 \mathrm{~m}$ depth combined with soil properties to explain soil water content. Selected variables for each best model are indicated with an X.

\begin{tabular}{cccccccc}
\hline Rank & ECa 1.5 m & CEC $^{\mathbf{1}}$ & Clay & OM $^{\mathbf{2}}$ & Salts & r2 & AICc $^{3}$ \\
\hline 1 & $X$ & - & - & $X$ & $X$ & 0.69 & -82.89 \\
2 & $X$ & - & - & - & - & 0.44 & -80.62 \\
3 & $X$ & - & - & - & $X$ & 0.55 & -80.55 \\
4 & $X$ & - & $X$ & - & $X$ & 0.64 & -80.3 \\
5 & $X$ & - & - & $X$ & - & 0.53 & -79.88 \\
\hline
\end{tabular}

${ }^{1}$ Cation exchange capacity; ${ }^{2}$ Organic Matter; ${ }^{3}$ corrected Akaike Information Criterion.

Results suggest that organic matter and salt content should be incorporated, even with low organic matter values $(1.6 \%)$ and salt concentration $\left(0.59 \mathrm{dS} \mathrm{m}^{-1}\right)$ levels that are below yield-impacting levels as observed in the studyfield. The spatial distribution of the soil properties influencing ECa may be different from SWC's spatial distribution, making the ECa interpretation more difficult. For example, high $\mathrm{pH}$, salt or sodium levels are commonly heterogeneously distributed across the fields [22]. To provide wider technical recommendations, it may be necessary to conduct further research on scenarios with different quantities of soil organic matter and soluble salts, as well as scenarios with different soil properties affecting the ECa against SWC relationship. Benefits from improving the SSMZ for irrigation by incorporating other soil properties have to be compared with the cost of sampling for those soil components. Even though remote sensing has been proven to estimate superficial salinity $[23,24]$ and organic matter content [25], they are not quantitatively precise enough yet [24].

The results from this study showed that soil ECa derived management zones were associated with macro-scale spatial variations in SWC along the crop season. However, it is worth noting that this was only true for the average SWC values within zones. Longchamps et al. [21] reported the existence of dynamic water management zones throughout the season, i.e., a continuous variability in the SWC patterns in time. To address this finer scale variability in the SWC, hence to achieve better VRI practices, 
more detailed information about the SWC status would be necessary. De Lara et al. [26] suggested the use of vegetation indices (i.e., Normalized Difference Vegetation Index, Red Edge Chlorophyll Index and Red Edge Normalized Difference Vegetation Index) for the real-time assessment of the SWC within each soil ECa derived water management zone. Combining the advent of new remote sensing technologies, such as drones and high spatial resolution satellite data, with new precision irrigation technologies (capable of varying irrigation rates at every nozzle), shows promise for the future of variable rate irrigation practices. However, more research combining these different technologies for crop production is needed for accurate management at the field level.

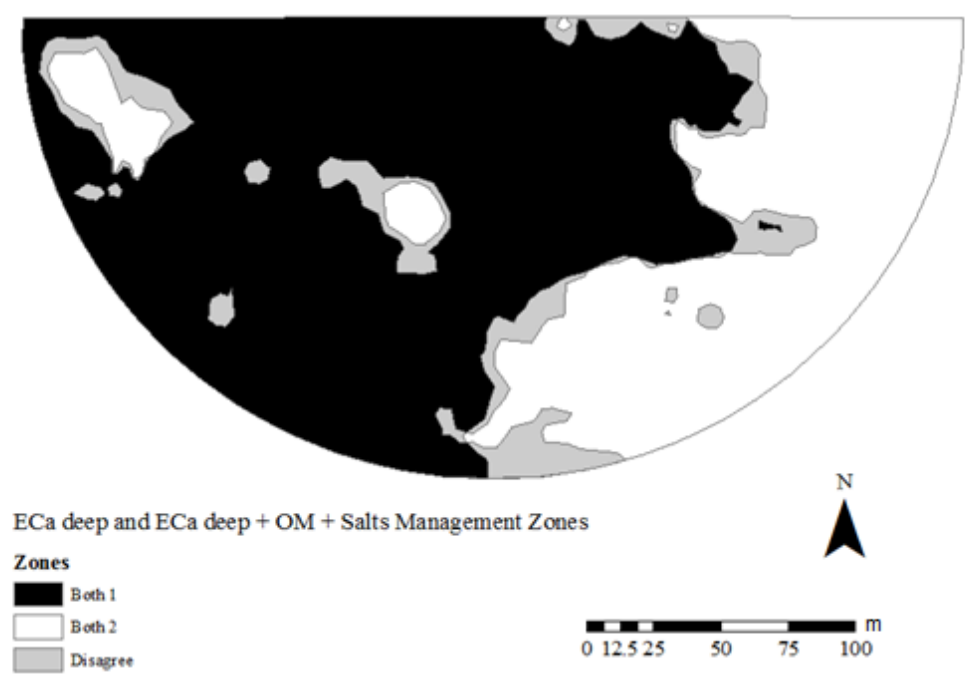

Figure 3. Comparison of management zones delineated with using soil ECa measured up to $1.5 \mathrm{~m}$ depth and management zones delineated using soil ECa measured up to $1.5 \mathrm{~m}$ depth in addition to organic matter and soil salinity for ARDEC. Differences in the two techniques are presented as gray color referred to as "disagree" in the legend.

\section{Conclusions}

The soil ECa derived management zones showed to be an effective method to characterize macro-scale in-field SWC variability between zones throughout the crop season. The Management Zones Analyst (MZA) software recommendations were more accurate than the fixed number of three zones typically proposed by commercial retailers. The deep ECa readings ( 0 to $150 \mathrm{~cm}$ ) outperformed the shallow ECa readings $(0$ to $75 \mathrm{~cm}$ ) in the assessment of SWC. Interpolated soil ECa readings coupled with organic matter and salt content data significantly improved the SWC assessment according to the ANOVA test. The soil ECa zones could potentially be used for precision irrigation, which consists in applying specific rates of water, based on the requirements of each zone. However, the process of deriving the management zones from the ECa should be determined based on the study of the ECa values distribution and descriptive statistics, which may vary along with the variability in soil hydraulic properties existing across farms.

Author Contributions: R.K. was the first author's adviser, designed the study, provided supervision for research, and input for the paper. L.L. was responsible to design the study, provide training, and outline the methodology, statistical analysis and laboratory analyses. A.d.L performed statistical analyses and wrote the paper.

Acknowledgments: This project was partly funded by Colorado State University Agricultural Experiment Station, Colorado Corn Growers Administrative Committee, the 21st Century Equipment Inc., Bridgeport, NE, USA, John Deere-Water Inc., Moline, IL, USA, the Fluid Fertilization Foundation and the USDA-Natural Resource Conservation Services-Conservation Innovation Grant.

Conflicts of Interest: The authors declare no conflict of interest. The founding sponsors had no role in the design of the study; in the collection, analyses, or interpretation of data; in the writing of the manuscript, and in the decision to publish the results. 


\section{References}

1. Groeteke, J.; Dotterer, L.; Shanahan, J. Variable rate irrigation. Crop Insights 2014, 24.

2. Peters, R.T.; Desta, K.; Nelson, L. Practical Use of Soil Moisture Sensors and Their Data for Irrigation Scheduling; Washington State University Extension: Pullman, WA, USA, 2013.

3. Schmitz, M.; Sourell, H. Variability in soil moisture measurements. Irrig. Sci. 2000, 19, 147-151. [CrossRef]

4. Fleming, K.L.; Westfall, D.G.; Wiens, D.W.; Rothe, L.E.; Cipra, J.E.; Heermann, D.F. Evaluating farmer developed management zone maps for precision farming. Precis. Agric. 1999, 335-343. [CrossRef]

5. Khosla, R.; Fleming, K.; Delgado, J.; Shaver, T.; Westfall, D. Use of site-specific management zones to improve nitrogen management for precision agriculture. J. Soil Water Conserv. 2002, 57, 513-518.

6. Hedley, C.; Yule, I.; Tuohy, M.; Vogeler, I. Key performance indicators for simulated variable-rate irrigation of variable soils in humid regions. Trans. ASABE 2009, 52, 1575-1584. [CrossRef]

7. Hedley, C.B.; Yule, I.J. Soil water status mapping and two variable-rate irrigation scenarios. Precis. Agric. 2009, 10, 342-355. [CrossRef]

8. LaRue, J.L. Variable rate irrigation 2010 field results. In Proceedings of the 23rd Annual Central Plains Irrigation Conference, Burlington, CO, USA, 22-23 February; American Society of Agricultural and Biological Engineers: St. Joseph, MI, USA, 2011; p. 1.

9. Martin, D.; Smith, T.; Kranz, W.; Irmak, S.; van Donk, S.; Shanahan, J. Soil water management. Crop Insights 2014, 24.

10. Corwin, D.; Lesch, S. Application of soil electrical conductivity to precision agriculture. Agron. J. 2003, 95, 455-471. [CrossRef]

11. Paine, J.G.; Goldsmith, R.S.; Scanlon, B.R. Electrical conductivity and gamma-ray response to clay, water, and chloride content in fissured sediments, trans-pecos texas. Environ. Eng. Geosci. 1998, 4, 225-239. [CrossRef]

12. Hezarjaribi, A.; Sourell, H. Feasibility study of monitoring the total available water content using non-invasive electromagnetic induction-based and electrode-based soil electrical conductivity measurements. Irrig. Drain. 2007, 56, 53-65. [CrossRef]

13. Sheets, K.R.; Hendrickx, J.M. Noninvasive soil water content measurement using electromagnetic induction. Water Resour. Res. 1995, 31, 2401-2409. [CrossRef]

14. Fridgen, J.J.; Kitchen, N.R.; Sudduth, K.A.; Drummond, S.T.; Wiebold, W.J.; Fraisse, C.W. Management zone analyst (mza). Agron. J. 2004, 96, 100-108. [CrossRef]

15. Bates, D.; Maechler, M.; Bolker, B.; Walker, S. Fitting linear mixed-effects models using "lme4". J. Stat. Softw. 2015, 67, 1-48. [CrossRef]

16. R Core Team. R: A Language and Environment for Statistical Computing; R Foundation for Statistical Computing: Vienna, Austria, 2016; ISBN 3-900051-07-0.

17. Russell, V.L. Least-squares means: The (r) package (lsmeans). J. Stat. Softw. 2016, 69, 1-33.

18. Barton, K. Mumin: Multi-Model Inference. 2016. Available online: https://r-forge.r-project.org/scm/viewvc. php / *checkout* / www / MuMIn-manual.pdf?revision=390\&root=mumin (accessed on 24 April 2018).

19. Burnham, K.P.; Anderson, D.R. Model Selection and Multimodel Inference: A Practical Information-Theoretic Approach; Springer Science \& Business Media: Berlin, Germany, 2003.

20. Team, R.C.; Worldwide, C. The R Stats Package; R Foundation for Statistical Computing: Vienna, Austria, 2015.

21. Longchamps, L.; Khosla, R.; Reich, R.; Gui, D. Spatial and temporal variability of soil water content in leveled fields. Soil Sci. Soc. Am. J. 2015, 79, 1446-1454. [CrossRef]

22. Waskom, R.M.; Bauder, T.; Davis, J.; Cardon, G. Diagnosing Saline and Sodic Soil Problems; Colorado State University Cooperative Extension: Pullman, WA, USA, 2003.

23. Mehrjardi, R.T.; Mahmoodi, S.; Taze, M.; Sahebjalal, E. Accuracy assessment of soil salinity map in yazd-ardakan plain, central Iran, based on landsat etm+ imagery. Am. Eurasian J. Agric. Environ. Sci. 2008, 3, 708-712.

24. Weng, Y.L.; Gong, P.; Zhu, Z.-L. A spectral index for estimating soil salinity in the yellow river delta region of china using eo-1 hyperion data. Pedosphere 2010, 20, 378-388. [CrossRef] 
25. Bhatti, A.; Mulla, D.; Frazier, B. Estimation of soil properties and wheat yields on complex eroded hills using geostatistics and thematic mapper images. Remote Sens. Environ. 1991, 37, 181-191. [CrossRef]

26. De Lara, A.; Khosla, R.; Longchamps, L. Soil Water Content and High-Resolution Imagery: Maize Yield; Department of Soil and Crop Sciences, Colorado State University: Fort Collins, CO, USA, 2016; Unpublished work. 